\title{
Improving the Competency of Nurses
}

Citation for published version (APA):

Porte, P. J., Verweij, L. M., Collares, C. F., de Bruijne, M. C., van der Vleuten, C. P. M., \& Wagner, C. (2020). Improving the Competency of Nurses. Journal of Infusion Nursing, 43(6), 357-368.

https://doi.org/10.1097/NAN.0000000000000395

Document status and date:

Published: 01/01/2020

DOI:

10.1097/NAN.0000000000000395

Document Version:

Publisher's PDF, also known as Version of record

Document license:

Taverne

Please check the document version of this publication:

- A submitted manuscript is the version of the article upon submission and before peer-review. There can be important differences between the submitted version and the official published version of record.

People interested in the research are advised to contact the author for the final version of the publication, or visit the DOI to the publisher's website.

- The final author version and the galley proof are versions of the publication after peer review.

- The final published version features the final layout of the paper including the volume, issue and page numbers.

Link to publication

\footnotetext{
General rights rights.

- You may freely distribute the URL identifying the publication in the public portal. please follow below link for the End User Agreement:

www.umlib.nl/taverne-license

Take down policy

If you believe that this document breaches copyright please contact us at:

repository@maastrichtuniversity.nl

providing details and we will investigate your claim.
}

Copyright and moral rights for the publications made accessible in the public portal are retained by the authors and/or other copyright owners and it is a condition of accessing publications that users recognise and abide by the legal requirements associated with these

- Users may download and print one copy of any publication from the public portal for the purpose of private study or research.

- You may not further distribute the material or use it for any profit-making activity or commercial gain

If the publication is distributed under the terms of Article $25 \mathrm{fa}$ of the Dutch Copyright Act, indicated by the "Taverne" license above, 


\title{
Improving the Competency of Nurses
}

\author{
Validation of a Competency Test for Infusion Pumps
}

\author{
Petra J. Porte, PhD • Lisanne M. Verweij, PhD • Carlos Fernando Collares, MD, PhD • \\ Martine C. de Bruijne, MD, PhD • Cees P.M. van der Vleuten, PhD • Cordula Wagner, PhD
}

\begin{abstract}
To decrease infusion pump administration errors, time-consuming training is often initiated. The aims of this study were twofold: to develop minimum competency requirements for programming and operation of infusion pumps and to develop and validate a test for nurses based on those requirements. The test was completed by 226 nurses between May and December 2017. This study demonstrates that testing is a promising method to assess the competency of nurses in using medical devices. Moreover, test acceptability among nurses is high. Using competency requirements to develop a test offers the potential to tailor training needs and reduce training time.

Key words: competency, device, examination, infusion pumps, safety
\end{abstract}

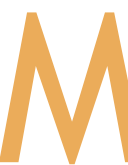

edication in hospitals of developed countries is often administered by an infusion pump. Estimations suggest that about $85 \%$ to $90 \%$ of all patients admitted to a hospital receive intravenous (IV) therapy by means of such pumps. ${ }^{1,2}$ Because

Author Affliations: Department of Public and Occupational Health, Amsterdam Public Health Research Institute (APH) Amsterdam UMC, VU University Medical Center (VUmc), Amsterdam, The Netherlands (Drs Porte, de Bruijne, and Wagner); Netherlands Institute for Health Services Research (NIVEL), Utrecht, The Netherlands (Drs Porte, Verweij, and Wagner); Department of Educational Development and Research, University of Maastricht, Maastricht, The Netherlands (Drs Collares and van der Vleuten).

Petra J. Porte, PhD, was a PhD trainee at NIVEL and the Amsterdam Public Health Research Institute. She obtained her $\mathrm{PhD}$ in medicine with research on the safe use of medical devices. Lisanne M. Verweij, PhD, is a VU University Health Science and Epidemiology scholar who provides expertise on evaluation and implementation of patient safety initiatives that combine medical technology. Dr Verweij is currently involved in research value-based health care (VBHC) at Erasmus MC hospital in Rotterdam, the Netherlands. She guides evidence-based practice during implementation of VBHC in collaboration with multidisciplinary disease teams. Carlos Fernando Collares, MD, PhD, is assistant professor of medical education in the Department of Educational Development and Research of the Faculty of Health, Medicine and Life Sciences at Maastricht University, as well as assessment specialist for the European Board of Medical Assessors. He is a pioneer in the implementation of computerized adaptive progress testing, which, by dynamically adjusting the difficulty of the test according to the test takers' performance, shortens the test, reduces testing time, and increases the reliability of scores, especially for students in the early academic years. Martine $\mathrm{C}$. de Bruijne, $\mathrm{MD}, \mathrm{PhD}$, is a professor of public health and quality of care at Amsterdam UMC. Dr de Bruijne is trained as a public health physician (2008), as well as in clinical epidemiology (PhD 1997) and health informatics (1991). Her research is directed at multidisciplinary teamwork, infusion pumps are frequently used to administer critical fluids, infusion pump-related adverse events can have significant consequences for patient safety. An observational study in the United States by Schnock et $\mathrm{al}^{3}$ showed a $60 \%$ error rate associated with medication administered

including the patient- and human-centered design to optimize quality and safety of care. Currently, her research is connected to national and local implementation of value-based health care. Cees P.M. van der Vleuten, PhD, has been at the University of Maastricht since 1982. In 1996 he was appointed professor of education and chair of the Department of Educational Development and Research in the Faculty of Health, Medicine and Life Sciences. Since 2005 he has been scientific director of the School of Health Professions Education. His primary expertise is in evaluation and assessment. He has published widely in this domain and holds numerous academic awards, including several career awards. He serves frequently as a consultant internationally. Cordula Wagner, $\mathrm{PhD}$, is executive director of NIVEL in Utrecht and works as a professor of patient safety at VU University Medical Center in Amsterdam. She is also head of the patient safety research center "Safety 4 Patients," a collaboration of the Institute for Research in Extramural Medicine (EMGO+/VUmc) and NIVEL. Dr Wagner's main interest is the improvement of organizational structures and cultures to improve health care for patients.

Financial support for the study was received from the Dutch Ministry of Health, Welfare and Sport. The funder had no role in the design and conduct of the study; collection, management, analysis, or interpretation of the data; or preparation, review, or approval of the manuscript.

The authors of this article have no other potential conflicts of interest to disclose.

Corresponding Author: Petra J. Porte, PhD, Department of Public and Occupational Health, Amsterdam Public Health Research Institute, VU University Medical Center, Van der Boechorststraat 7, 1081 BT Amsterdam, The Netherlands (petraporte@gmail.com).

DOI: $10.1097 /$ NAN.0000000000000395 
through infusion pumps. Another study in the Netherlands showed that about $13 \%$ of adverse medical device events are caused by infusion pumps. ${ }^{1,4}$ Additionally, a study by Taxis and Barber ${ }^{5}$ showed that at least 1 error occurred in $49 \%$ of IV medication doses. Although exact numbers are unknown, adverse events with infusion pumps are most likely a combination of device failure and human factors. ${ }^{6}$ A study by Björkstén et al identified human factors that contributed in $95 \%$ of medication-related errors, the most common factors being "negligence, forgetfulness or lack of attentiveness," "proper protocol not followed," and "lack of knowledge." ${ }^{\prime(p 5)}$ For medical devices, like infusion pumps, errors are often caused by human-technology interaction. ${ }^{7}$

To reduce errors in using medical devices, training of all health care staff is often initiated. . $^{8} 9$ Training could also help improve the competency of nurses to work with infusion pumps. Reviews of the literature illustrate that training improves knowledge and skills of nurses ${ }^{10-12}$ and influences clinical outcomes, such as infection rates. ${ }^{13,14}$ Although training could reduce the numbers of errors, it is resource intensive in an environment with an increasing number of medical devices, while less time is available for training. ${ }^{15}$ Moreover, mandatory training programs may lack relevance to the specific needs of nurses and might not result in improved practice. ${ }^{16}$ Whether a training is relevant depends on the competency of the individual nurse. If valid and reliable, a competency test could be used to assess competency and to tailor training needs. ${ }^{17,18}$ It also has the advantages of the "testing effect," which is improved long-term retention of knowledge after taking a test. ${ }^{19} \mathrm{~A}$ national competency test for the use of infusion pumps is currently not available in the Netherlands.

Competency is defined as a complex combination of knowledge, performance, skills, values, and attitudes. ${ }^{20}$ According to Miller's pyramid of competency, the first step in competency is "knows," followed by "knows how," "shows how," and "does." 21(p1) The evaluation of knowledge is particularly done by objective, reliable test methods, whereas the assessment of skills is done with less objective methods. ${ }^{21}$ This study focuses on assessing knowledge, the first and second steps of the Miller's pyramid. To assess nurses' knowledge of infusion pumps, the competency requirements of working with infusion pumps should be known. ${ }^{22}$ The aims of this study were to develop minimum competency requirements for using infusion pumps and to develop and validate a competency test for using infusion pumps based on those competency requirements. The research considered the following question: what is the acceptability and the ability to differentiate competency of an infusion pump competency test for nurses?

\section{METHODS}

\section{Competency Requirements}

The minimum competency requirements were developed based on literature and expert opinion of infusion pump experts.

\section{Participants in Expert Group}

The infusion pump expert group consisted of 5 experts: 3 nurses, 1 clinical physicist, and 1 training and testing expert. The nurses were all selected by the Dutch Association of Nurses and Carers. Two nurses worked in a general hospital and were experienced in the use of infusion pumps, and the other nurse worked on a specialized home care infusion pump nursing team. The clinical physicist worked in an academic hospital with a focus on the safe use of infusion pumps. The meetings were led by 2 researchers.

\section{Development of Competency Requirements}

The development of competency requirements was based on cognitive task analysis, which has 5 common steps: (1) collect primary knowledge, (2) identify knowledge representations, (3) apply focused knowledge elicitation methods, (4) analyze and verify data acquired, and (5) format results for the intended application. ${ }^{23}$

In the first step, international literature and guidelines were collected to identify existing competency requirements, procedures, and areas of risk. An overview of knowledge and skills necessary for the safe application of infusion pumps was provided by one of the researchers. This was followed by a meeting with the expert group for additional input. In the second step, the expert group discussed and identified minimum knowledge and skills requirements for safe application of infusion pumps. In the third step, a researcher drafted a concept version of the levels of complexity of the competency requirements based on Bloom's taxonomy. ${ }^{24}$ Only the first 3 levels of complexity (remembering, understanding, and applying) were used for the competency requirements. Action words such as name, explain, and demonstrate corresponding with the respective levels of complexity were used to describe the competency requirements. In the fourth step, a second expert group meeting was held for verification, refinement, and revision of the concept competency requirements. Additionally, the competency requirements were sent to the scientific associations of nurses and clinical physicists for feedback and approval. One researcher adjusted the concept version. The final competency requirements were sent to all experts for approval. In the fifth and final step, the knowledge competency requirements were used to develop the competency test.

\section{COMPETENCY TEST}

\section{Development}

The competency requirements were used as a basis for the competency test, which was an online test provided by a Dutch commercial publisher that specialized in the development of e-learning and online tests. The expert group was asked to prioritize the competency requirements as low, medium, or high priority. The average priority of the different experts was taken as the priority of the competency requirement. Requirements with the highest priority were 
represented in 3 questions, the medium priority in 2 questions, and the lowest priority in 1 question. Competency requirements from the third level of complexity (applying) were excluded from the competency test because such requirements can be examined only in a practical examination. Competency requirements that were applicable only for specific hospitals or types of infusion pumps also were excluded from the competency test. Questions were based on international literature and protocols. When possible, existing questions from the publisher were used; if not possible, new questions were developed. Exam questions were developed by an educational measurement specialist and a text editor. Questions were multiple choice, true/false, matching, or pointing. All of the questions were reviewed by the expert group via email and, when necessary, discussed and adapted.

\section{Participants}

Three groups of nurses were invited to complete the competency test: experienced nurses (with more than 10 years of experience), less experienced nurses (with less than 5 years of experience), and nursing students with no experience. Between May and December 2017, nurses were invited to participate through hospitals, social media (eg, LinkedIn, Facebook, and Twitter), and a magazine for nurses. A flyer containing information about the research and the inclusion criteria was disseminated. Inclusion criteria were the following: nurses working in a hospital with infusion pumps, with less than 5 or more than 10 years of experience. Nurses were excluded from participation if they had between 5 and 10 years of experience. Nurses could send an email to one of the researchers to participate. Included nurses received an email with login credentials and a link to the online test. Nursing students were second-year students from a university of applied science. Students were asked via email to participate in a lecture on patient safety, including the competency test. There is no gold standard for the number of participants required to use item response theory; advised is at least 100 participants. ${ }^{25}$ Our aim was 100 participants in each group to take all questions into account. When each group reached at least 50 participants, the analysis was performed by selecting the most discriminative questions as explained below.

All of the participants answered the same questions but in a random order to prevent (answers of) questions from influencing the answer of other questions. Before the test started, the demographics of the participants were requested. Participants were also asked the extent to which they agreed to the statement: "I am competent to work with an infusion pump." Two additional statements were presented after the nurses completed the competency test. The first statement was: "A nurse should pass this exam before he/ she is allowed to work with an infusion pump." The second statement was: "Health care will become safer if a nurse must pass this exam before he/she is allowed to work with an infusion pump." All statements could be answered on a 5-point Likert scale (strongly disagree to strongly agree) and were used to examine the acceptability of the competency test.

\section{Psychometric Characteristics and Validation}

Classical test theory (CTT) and item response theory (IRT) were used to determine the characteristics of the questions and to validate the competency test. CTT was used to describe features of all questions and to select the most informative questions for further analysis with IRT, as explained in more detail below. CTT is based on the idea that a person's score is the sum of the correct answered questions. IRT takes into account the difficulty of questions when calculating test scores and might therefore be more valid and provide more information to test takers and institutions. Analysis was done with SPSS 22 (IBM Corp, Armonk, NY) for descriptives and CTT, R 3.4.2, and R studio 3.4.2 (R Studio, Boston, MA) for IRT. The R-packages mirt, Itm, psych, lavaan, qgraph, igraph, and ega were used during analysis.

\section{Classical Test Theory}

With CTT we calculated different parameters for the questionnaire and individual questions. Cronbach's $\alpha$ is calculated as an estimate of the reliability of the test as a whole. For the individual questions, $P$ and Rit-values were calculated. The $P$ value represents the share of candidates who answered the question correctly. The Rit-value reflects the performance of the question versus the test as a whole. It tells us to what extent a question contributes to the discrimination of the level of performance. $P$ and Rit-values were used to select the most informative questions of the exam for further analysis. This selection was necessary because of the large number of questions compared with the number of participants. To contain content validity for each competency requirement, the most informative question was selected, except for competency requirements with the lowest priority. For this category only questions with a $P$ value between .3 and .8 and a Rit-value above 0.3 were selected. For the high and medium priority competency requirements, the questions with the highest Rit-value and a $P$ value between .3 and .8 were selected. When such a question was not available, a question with $P$ and Ritvalues closest to those values was selected.

\section{Model Assessment Item Response Theory}

Before IRT was done, data were explored with principal component analysis, and the Kaiser-Meyer-Olkin measure was calculated to ensure sample adequacy. Several parameters can be assessed in IRT. The $\theta$-parameter is a parameter for question discrimination. This parameter indicates how well the question discriminates between knowledgeable and less-knowledgeable participants. The $\beta$-parameter is known as the difficulty parameter. It corresponds with the knowledge level at which the probability of answering the question correctly is the same as the probability of answering 
the question incorrectly. The c-parameter, or guessing factor, describes the probability that a respondent with no knowledge will answer the question correctly. ${ }^{26}$ Parameters can be estimated, depending on the chosen model. Three models were compared: a 1-parameter (Rasch model, only $\theta$-parameter), a 2-parameter (2-PL model, $\theta$ - and $\beta$-parameters) and a 3-parameter (3-PL model, $\theta-, \beta$ - and c-parameters) model. The 3 models were compared applying a likelihood-ratio test and comparing the differences in the Akaike information criterion (AIC). The AIC estimates the quality of each model relative to each of the other models. Lower AIC values indicate a better-fitting model. We calculated the root mean square error of approximation (RMSEA) and the comparative fit index (CFI) to examine whether the model had a good fit. Literature has shown that, for adequate fit, the criteria for RMSEA is $<0.05$ and for $\mathrm{CFI} \geq 0.95$. $^{27}$

\section{Validation}

The scores of participants in IRT are represented by the $\theta$-parameter. This reflects the difficulty of the questions $(\theta)$ that a participant answers correctly. After the normal distribution of the group scores was assessed, the mean and standard deviation for each group were calculated. One-way ANOVA tests were used to see whether groups of participants had different knowledge levels.

\section{RESULTS}

\section{Competency Requirements}

The development of competency requirements for infusion pump use resulted in a list of 64 requirements, ${ }^{28}$ which were distributed among 3 categories of priority: high, medium, and low. From this list, 23 requirements were used to develop the knowledge test. Forty-one requirements were not included in the knowledge test because those requirements represented a skill or were hospital or infusion pump specific (Table 1). One requirement (2.4) was excluded after the test started because the question was not clear.

\section{COMPETENCY TEST}

\section{Participants}

Of the 316 nurses and nursing students who indicated they wanted to participate, 226 (70.8\%) completed the competency test. The competency test was completed by 75 nursing students, 62 nurses with 0 to 5 years of experience, and 89 nurses with more than 10 years of experience. Demographics of the participants can be found in Table 2 . Most participants were female (89.4\%), under 25 years of age $(43.4 \%)$, and worked in a general hospital (36.7\%). Participants could indicate on a 5-point Likert scale whether they think they are competent to work with an infusion pump. Students were less competent than nurses with 0 to 5 years of experience $(P<.001)$ and nurses with more than
10 years of experience $(P=.002)$. There was no difference between the self-declared competency of nurses with less than 5 or more than 10 years of experience $(P=.51)$. Most nurses and nursing students agreed that a nurse should pass this exam before working with an infusion pump and that health care will become safer if a nurse must pass this exam before he or she is allowed to work with an infusion pump. There were no significant differences for these statements between groups.

\section{Psychometric Characteristics and Validation}

$P$ values varied between .19 and .99 and Rit-values between 0.03 and 0.66 (Table 3). $P$ and Rit-values were used to select the most informative questions of the exam for further analysis. For high- and medium-priority questions, 1 question for each competency requirement was selected based on the highest Rit-value and a $P$ value between .3 and .8. For low priority questions, only questions with a $P$ value between .3 and .8 and a Rit-value above 0.3 were selected. This resulted in a total of 20 questions for IRT analysis. The Cronbach's $\alpha$ for the whole competency test was $0.692(95 \% \mathrm{Cl}, 0.632-0.747)$, which indicates a questionable internal consistency. The Cronbach's $\alpha$ of the 20 selected questions was $0.755(95 \% \mathrm{Cl}, 0.706-0.799)$, which represents an acceptable internal consistency. The principal component analysis on the 20 questions in the sample of 226 participants showed one principal component. The Kaiser-Meyer-Olkin measure was 0.79, which demonstrated sample adequacy for the analysis. After the exploration of the data, the best-fitting model for the data was assessed. The 2-PL model demonstrated a significantly better fit $(P<.001)$ than the Rasch model. The 3-PL model demonstrated no significantly better fit than the 2-PL model $(P=.34)$ and had a higher AIC, so the 2-PL model was selected. For the 2-PL model the RMSEA was 0.034 (95\% Cl, 0.017-0.047), and the CFI was 0.954, which indicated a good fit of the model.

\section{Test Results}

Table 4 shows the mean scores of the 3 different groups when using 2 different methods to calculate test scores: CTT (20 selected questions) and IRT ( 20 selected questions). The $P$ values, Rit-values, $\theta$-parameters, and $\beta$-parameters for the different questions are shown in Table 3 The CTT scores were significantly different among the different groups $(P<$ .001). Moreover, the IRT scores were significantly different among the groups $(P<.001)$. Figure 1 represents the precision (information) and standard error with which the ability of a person can be estimated. This ability is estimated with most precision when the $\theta$-parameter is around -1 .

\section{DISCUSSION}

The results of the test indicate that different levels of knowledge can be distinguished with the developed infusion 
TABLE 1

\section{Competency Requirements With the Corresponding Priority Within in the} Exam or the Reason of Exclusion for the Exam

\section{No.} Requirement

\section{Category}

Basis

\begin{tabular}{l|l|l}
\hline 1.1 & The nurse can name what the indications are for the use of an infusion pump. & Low priority \\
\hline 1.2 & $\begin{array}{l}\text { The nurse can name where information about the infusion pump can be found or where this can } \\
\text { be retrieved. }\end{array}$ & Low priority \\
\hline 1.3 & $\begin{array}{l}\text { The nurse can name which infusion pump is suitable for which application (eg, for the administra- } \\
\text { tion of medication/blood). }\end{array}$ & Low priority \\
\hline 1.4 & The nurse can name what the risks are of different administration routes. & High priority \\
\hline 1.5 & The nurse can name globally what is in the various protocols. & Hospital dependent \\
\hline 1.6 & The nurse can calculate the correct concentration and administration speed for a drug/fluid. & $\begin{array}{l}\text { Already examined in } \\
\text { Dutch hospitals }\end{array}$ \\
\hline 1.7 & The nurse can explain the functionalities of the infusion pump. & Pump dependent \\
\hline
\end{tabular}

Preparation

\begin{tabular}{|c|c|c|}
\hline 2.1 & The nurse can explain the instructions of the doctor. & Skill \\
\hline 2.2 & The nurse can reason what the correct treatment is based on the instructions of the doctor. & Medium priority \\
\hline 2.3 & The nurse can explain how medication has to be made and checked. & High priority \\
\hline 2.4 & $\begin{array}{l}\text { The nurse can name how it can be checked whether medicines may be administered together via } \\
1 \text { infusion line. }\end{array}$ & Low priority \\
\hline 2.5 & The nurse can explain how to work in an aseptic manner. & Medium priority \\
\hline 2.6 & The nurse can name which equipment belongs with which infusion pump. & Pump dependent \\
\hline 2.7 & The nurse can name which equipment is suitable for which medication/fluids. & Pump/hospital dependent \\
\hline 2.8 & $\begin{array}{l}\text { The nurse can name which equipment is required in order to be able to connect an infusion pump } \\
\text { correctly. }\end{array}$ & Pump dependent \\
\hline 2.9 & The nurse can name whether non-return valves have to be used. & Medium priority \\
\hline 2.10 & The nurse can demonstrate how the infusion pump has to be attached. & Pump dependent/skill \\
\hline 2.11 & The nurse can demonstrate how the infusion system has to be filled. & Pump dependent/skill \\
\hline \multicolumn{3}{|c|}{ Usage } \\
\hline 3.1 & The nurse can demonstrate how one must work following the protocol. & Hospital dependent/skill \\
\hline 3.2 & $\begin{array}{l}\text { The nurse can explain whether the needle and system are still in a good position or when it has to } \\
\text { be checked. }\end{array}$ & Medium priority \\
\hline 3.3 & $\begin{array}{l}\text { The nurse can demonstrate how the needle and system are still in a good position or when it has } \\
\text { to be checked. }\end{array}$ & Skill \\
\hline 3.4 & The nurse can explain the correct program to setup the infusion pump. & Pump dependent \\
\hline 3.5 & The nurse can name the use for each button on the infusion pump. & Pump dependent \\
\hline 3.6 & The nurse can demonstrate how the infusion pump has to be set. & Pump dependent/skill \\
\hline 3.7 & The nurse can demonstrate how adjustments have to be made to the infusion pump. & Pump dependent/skill \\
\hline 3.8 & The nurse can explain why the infusion pump settings have to be double-checked. & High priority \\
\hline 3.9 & The nurse can demonstrate how an extra drug has to be connected. & Pump dependent/skill \\
\hline 3.10 & $\begin{array}{l}\text { The nurse can name what the effects can be when several fluids are administered via one infusion } \\
\text { line (multi-infusion). }\end{array}$ & $\begin{array}{l}\text { No priority (high similarity } \\
\text { to } 3.12,3.13 \text { and } 3.14 \text { ) }\end{array}$ \\
\hline 3.11 & $\begin{array}{l}\text { The nurse can demonstrate which line/infusion pump belongs to which medication/fluid and how } \\
\text { this can be checked. }\end{array}$ & Skill \\
\hline 3.12 & $\begin{array}{l}\text { The nurse can explain that, when several drugs are running through } 1 \text { infusion line, the concentra- } \\
\text { tion ratio of the drugs in the line is the result of the settings from the infusion pumps which are } \\
\text { connected to the same line. }\end{array}$ & Medium priority \\
\hline
\end{tabular}

Copyright $\odot 2020$ Infusion Nurses Society. Unauthorized reproduction of this article is prohibited. 
TABLE 1

\section{Competency Requirements with the Corresponding Priority Within in the} Exam or the Reason of Exclusion for the Exam (Continued)

\begin{tabular}{|c|c|}
\hline No. & Requirement \\
\hline 3.13 & $\begin{array}{l}\text { The nurse can explain that, when several drugs are running through } 1 \text { infusion line, in the case } \\
\text { that an infusion pump setting changes it will take some time before the right concentration ratio } \\
\text { of medication is given to the patient }\end{array}$ \\
\hline 3.14 & $\begin{array}{l}\text { The nurse can explain that when several drugs run through } 1 \text { infusion line a temporary dosing } \\
\text { error can occur at infusion pumps which are not modified. }\end{array}$ \\
\hline 3.15 & The nurse can explain the consequences of rinsing or not rinsing the infusion line. \\
\hline 3.16 & The nurse can demonstrate how free-flow can be prevented. \\
\hline
\end{tabular}

Category

Medium priority

High priority

Medium priority

Medium priority

\begin{tabular}{|c|c|c|}
\hline 4.1 & The nurse can explain what all the alarms mean. & Pump dependent \\
\hline 4.2 & The nurse can demonstrate how to handle the situation when there is an alarm. & High priority \\
\hline 4.3 & The nurse can demonstrate what has to be done in the case of an occlusion. & High priority \\
\hline 4.4 & The nurse can name the dangers of occlusion. & $\begin{array}{l}\text { No priority (high similarity } \\
\text { to } 4.3 \text { ) }\end{array}$ \\
\hline 4.5 & $\begin{array}{l}\text { The nurse can name which alarm settings the health professional can or cannot modify } \\
\text { themselves. }\end{array}$ & Pump/hospital dependent \\
\hline 4.6 & The nurse can name when the alarm settings may be adjusted. & Pump/hospital dependent \\
\hline 4.7 & The nurse can demonstrate how the alarm settings can be adjusted. & Pump dependent \\
\hline 4.8 & The nurse can demonstrate how the alarm settings can be checked. & Pump dependent \\
\hline 4.9 & The nurse can explain what the alarm settings are and why these are the settings. & Hospital dependent \\
\hline 4.10 & $\begin{array}{l}\text { The nurse can name that there are different types of alarm settings and that these settings vary } \\
\text { between departments. }\end{array}$ & Low priority \\
\hline 4.11 & The nurse can name what the consequences are when the alarm settings are adjusted. & High priority \\
\hline \multicolumn{3}{|c|}{ After use } \\
\hline 5.1 & The nurse can demonstrate how the infusion has to be rinsed through. & Pump dependent/skill \\
\hline 5.2 & The nurse can demonstrate how the infusion pump has to be disconnected. & Pump dependent/skill \\
\hline 5.3 & The nurse can demonstrate how the infusion pump has to be cleaned. & Pump dependent/skill \\
\hline 5.4 & The nurse can demonstrate how the infusion pump has to be stored. & $\begin{array}{l}\text { Pump/hospital } \\
\text { dependent/skill }\end{array}$ \\
\hline
\end{tabular}

Transport/transfer/mobility

\begin{tabular}{|c|c|c|}
\hline 6.1 & $\begin{array}{l}\text { The nurse can demonstrate how one should handle a patient who has come from outside the hos- } \\
\text { pital and who has an infusion pump. }\end{array}$ & Hospital dependent/skill \\
\hline 6.2 & The nurse can demonstrate how a patient with an infusion pump can be transported safely. & Skill \\
\hline 6.3 & $\begin{array}{l}\text { The nurse can demonstrate how a patient with an infusion pump has to be prepared for diagnostic } \\
\text { tests. }\end{array}$ & Low priority \\
\hline 6.4 & $\begin{array}{l}\text { The nurse can demonstrate how a patient with an infusion pump must be transferred when being } \\
\text { moved to another department/another hospital. }\end{array}$ & Hospital dependent/skill \\
\hline 6.5 & The nurse can explain to the patient how to be mobile with an infusion pump. & Pump dependent \\
\hline \multicolumn{3}{|c|}{ Power supply } \\
\hline 7.1 & The nurse can explain how the infusion pump is provided with power. & Low priority \\
\hline 7.2 & The nurse can demonstrate how to handle the battery of an infusion pump. & Pump dependent/skill \\
\hline 7.3 & The nurse can demonstrate how the infusion pump has to be charged. & Pump dependent/skill \\
\hline 7.4 & The nurse can demonstrate which wall socket has to be used. & Hospital dependent/skill \\
\hline 7.5 & The nurse can explain how to recognize when the infusion pump battery is about to run down. & Pump dependent \\
\hline 7.6 & The nurse can name what has to be done in the event of a power failure. & Pump/hospital dependent \\
\hline
\end{tabular}

(continues)

Copyright $\odot 2020$ Infusion Nurses Society. Unauthorized reproduction of this article is prohibited. 
TABLE 1

\section{Competency Requirements with the Corresponding Priority Within in the} Exam or the Reason of Exclusion for the Exam (Continued)

\begin{tabular}{l|l|l|l|l|l}
\hline No. & Requirement & \multicolumn{1}{l}{ Category } \\
\hline 7.7 & $\begin{array}{l}\text { The nurse can discuss why the plug has to be disconnected on the side of the wall socket and not } \\
\text { on the side of the infusion pump. }\end{array}$ & No scientific proof \\
\hline Malfunction & $\begin{array}{l}\text { The nurse can demonstrate whether an infusion pump is functioning well or when it needs to be } \\
\text { checked. }\end{array}$ & Pump dependent/skill \\
\hline 8.1 & \begin{tabular}{l} 
The nurse can recognize when there is a problem with the pump. \\
\hline 8.2
\end{tabular} & $\begin{array}{l}\text { The nurse can name what must be done if the infusion pump is not functioning well or if there is } \\
\text { doubt concerning this. }\end{array}$ & Pump/hospital dependent
\end{tabular}

\section{TABLE 2}

\section{Demographics and Mean Scores and Agreement to Statements About Competency and the Competency Exam $(n=226)$}

\begin{tabular}{|c|c|c|c|c|}
\hline & Student $^{\mathrm{a}}$ & $\begin{array}{l}0-5 \text { years of } \\
\text { experience }\end{array}$ & $\begin{array}{l}10+\text { years of } \\
\text { experience }\end{array}$ & Total \\
\hline Number of participants & 75 & 62 & 89 & 226 \\
\hline Female, $\mathrm{n}(\%)$ & $73(97)$ & $51(82)$ & $78(88)$ & $202(89)$ \\
\hline \multicolumn{5}{|l|}{ Age, $n(\%), y$} \\
\hline Under 25 & $67(89)$ & $31(50)$ & 0 & $98(43)$ \\
\hline $25-34$ & $4(5.3)$ & $30(48)$ & $7(8)$ & $41(18)$ \\
\hline $35-44$ & $3(4.0)$ & $1(2)$ & $27(30)$ & $31(14)$ \\
\hline $45-54$ & $1(1.3)$ & 0 & $33(37)$ & $34(15)$ \\
\hline 55 or older & 0 & 0 & $22(25)$ & $22(10)$ \\
\hline \multicolumn{5}{|l|}{ Years of experience, $n(\%)$} \\
\hline $0-1$ years & $42(56)$ & $7(11)$ & - & $49(22)$ \\
\hline $1-2$ years & $26(35)^{b}$ & $13(21)$ & - & $39(17)$ \\
\hline $2-5$ years & $7(9)^{b}$ & $42(68)$ & - & $49(212)$ \\
\hline $10-20$ years & - & - & 30 (34) & $30(13)$ \\
\hline $20-30$ years & - & - & $30(34)$ & $30(13)$ \\
\hline $30+$ years & - & - & $29(33)$ & $29(123)$ \\
\hline \multicolumn{5}{|l|}{ Workplace, n (\%) } \\
\hline General hospital & - & $32(52)$ & $51(57)$ & $83(37)$ \\
\hline Tertiary teaching hospital & - & $16(26)$ & $22(25)$ & $38(17)$ \\
\hline University hospital & - & $14(23)$ & $16(18)$ & $30(13)$ \\
\hline \multicolumn{5}{|l|}{ Agreement to statement on 1-5 scale (mean, SD) } \\
\hline I am proficient to work with an infusion pump & $1.47(0.70)$ & $4.45(0.53)$ & $4.39(0.54)$ & $3.47(1.47)$ \\
\hline $\begin{array}{l}\text { A nurse should pass this exam before he/she is allowed to work with an infusion } \\
\text { pump }\end{array}$ & $4.35(0.80)$ & $3.61(0.98)$ & $3.74(0.91)$ & $3.91(0.95)$ \\
\hline $\begin{array}{l}\text { Health care will become safer if a nurse has to pass this exam before he/she is } \\
\text { allowed to work with an infusion pump }\end{array}$ & $4.21(0.70)$ & $3.82(0.84)$ & $3.83(0.83)$ & $3.96(0.81)$ \\
\hline
\end{tabular}


TABLE 3

\section{Question Characteristics of the Competency Test}

\begin{tabular}{|c|c|c|c|c|c|}
\hline \multirow[b]{2}{*}{ Item } & \multirow[b]{2}{*}{ Proficiency requirement ${ }^{a}$} & \multicolumn{2}{|c|}{ Classical test theory } & \multicolumn{2}{|c|}{ Item response theory } \\
\hline & & $P$ value & Rit-value & $\theta$-parameter & $\beta$ - parameter \\
\hline \multicolumn{6}{|c|}{ Priority 1 (high) } \\
\hline \multirow[t]{3}{*}{1.4} & \multirow[t]{3}{*}{ The nurse can name the risks of different administration routes. } & .52 & 0.58 & 2.07 & -0.68 \\
\hline & & .45 & 0.32 & $x$ & $x$ \\
\hline & & .54 & 0.49 & $x$ & $x$ \\
\hline \multirow[t]{3}{*}{2.3} & \multirow[t]{3}{*}{ The nurse can explain how medication has to be made and checked. } & .99 & 0.03 & $x$ & $x$ \\
\hline & & .19 & 0.26 & $x$ & $x$ \\
\hline & & .86 & 0.55 & 1.47 & 2.45 \\
\hline \multirow[t]{3}{*}{3.8} & \multirow{3}{*}{$\begin{array}{l}\text { The nurse can name why the infusion pump settings have to be double- } \\
\text { checked. }\end{array}$} & .64 & 0.05 & $x$ & $x$ \\
\hline & & .85 & 0.12 & $x$ & $x$ \\
\hline & & .82 & 0.59 & 1.54 & 2.12 \\
\hline \multirow[t]{3}{*}{3.14} & \multirow{3}{*}{$\begin{array}{l}\text { The nurse can explain that when several drugs run through } 1 \text { infusion } \\
\text { line a temporary dosing error can occur at infusion pumps which are not } \\
\text { modified. }\end{array}$} & .77 & 0.10 & $x$ & $x$ \\
\hline & & .82 & 0.33 & 0.42 & 1.56 \\
\hline & & .46 & 0.22 & $x$ & $x$ \\
\hline \multirow[t]{3}{*}{4.2} & \multirow{3}{*}{$\begin{array}{l}\text { The nurse can demonstrate how to handle the situation when there is an } \\
\text { alarm. }\end{array}$} & .65 & 0.45 & 0.88 & 0.75 \\
\hline & & .21 & 0.15 & $x$ & $x$ \\
\hline & & .68 & 0.28 & $x$ & $x$ \\
\hline \multirow[t]{3}{*}{4.3} & \multirow{3}{*}{$\begin{array}{l}\text { The nurse can demonstrate what has to be done in the case of an } \\
\text { occlusion. }\end{array}$} & .79 & 0.50 & 0.74 & 1.49 \\
\hline & & .64 & 0.11 & $x$ & $x$ \\
\hline & & .41 & 0.15 & $x$ & $x$ \\
\hline \multirow[t]{3}{*}{4.11} & \multirow{3}{*}{$\begin{array}{l}\text { The nurse can explain the consequences when the alarm settings are } \\
\text { adjusted. }\end{array}$} & .82 & 0.30 & $x$ & $x$ \\
\hline & & .27 & 0.22 & $x$ & $x$ \\
\hline & & .52 & 0.39 & 0.84 & 0.10 \\
\hline \multicolumn{6}{|c|}{ Priority 2 (medium) } \\
\hline \multirow[t]{2}{*}{2.2} & \multirow{2}{*}{$\begin{array}{l}\text { The nurse can reason what the correct treatment is based on the instruc- } \\
\text { tions of the doctor. }\end{array}$} & .66 & 0.36 & 0.65 & 0.72 \\
\hline & & .94 & 0.32 & $x$ & $x$ \\
\hline \multirow[t]{2}{*}{2.5} & \multirow[t]{2}{*}{ The nurse can explain how to work in an aseptic manner. } & .90 & 0.54 & 1.22 & 2.70 \\
\hline & & .69 & 0.24 & - & $x$ \\
\hline \multirow[t]{2}{*}{2.9} & \multirow[t]{2}{*}{ The nurse can name whether non-return valves have to be used. } & .24 & 0.39 & 0.89 & -1.32 \\
\hline & & .42 & 0.11 & $x$ & $\mathrm{x}$ \\
\hline 3.2 & The nurse can explain when the needle and system are still in a good & .78 & 0.57 & 1.84 & 2.01 \\
\hline & & .31 & 0.05 & $x$ & $x$ \\
\hline 3.12 & The nurse can explain that, when several drugs are running through 1 & .36 & 0.28 & 0.32 & -0.60 \\
\hline & $\begin{array}{l}\text { infusion line, the concentration ratio of the drugs in the line is the result } \\
\text { of the settings from the infusion pumps which are connected to the } \\
\text { same line. }\end{array}$ & .92 & 0.38 & $x$ & $x$ \\
\hline 3.13 & The nurse can explain that, when several drugs are running through one & .19 & 0.10 & $x$ & $x$ \\
\hline & $\begin{array}{l}\text { infusion line, in the case that an infusion pump setting changes it will } \\
\text { take some time before the right concentration ratio of medication is } \\
\text { given to the patient. }\end{array}$ & .31 & 0.32 & 0.59 & -0.86 \\
\hline 3.15 & The nurse can explain the consequences of rinsing or not rinsing the & .88 & 0.24 & 0.54 & 2.06 \\
\hline & infusion line. & .47 & 0.13 & $x$ & $x$ \\
\hline 3.16 & The nurse can demonstrate how free-flow can be prevented. & .39 & 0.15 & $x$ & $x$ \\
\hline & & .75 & 0.66 & 2.64 & 2.18 \\
\hline
\end{tabular}

Copyright $\odot 2020$ Infusion Nurses Society. Unauthorized reproduction of this article is prohibited. 
TABLE 3

\section{Question Characteristics of the Competency Test (Continued)}

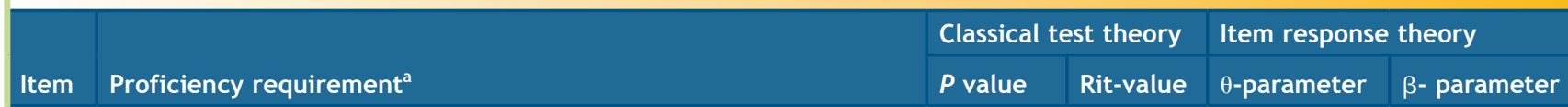

Priority 3 (low)

\begin{tabular}{l|l|l|l|l|l}
\hline 1.1 & $\begin{array}{l}\text { The nurse can name what the indications are for the use of an infusion } \\
\text { pump. }\end{array}$ & .38 & 0.51 & 1.43 & -0.68 \\
\hline 1.2 & $\begin{array}{l}\text { The nurse can name where information about the infusion pump can be } \\
\text { found or where this can be retrieved. }\end{array}$ & .91 & 0.44 & $x$ \\
\hline 1.3 & $\begin{array}{l}\text { The nurse can name which infusion pump is suitable for which } \\
\text { application (eg, administration of medication/blood). }\end{array}$ & .60 & 0.40 & 1.02 & $x$ \\
\hline 2.4 & $\begin{array}{l}\text { The nurse can explain whether medicines may be administered together } \\
\text { via } 1 \text { infusion line. }\end{array}$ & $x$ & $x$ & $x$ & 0.50 \\
\hline 4.10 & $\begin{array}{l}\text { The nurse can explain different types of alarm settings and how these } \\
\text { settings vary between departments. }\end{array}$ & .39 & 0.35 & 0.45 & $x$ \\
\hline 6.3 & $\begin{array}{l}\text { The nurse can demonstrate how a patient with an infusion pump has to } \\
\text { be prepared for diagnostic tests. }\end{array}$ & .53 & 0.04 & $x$ & -0.45 \\
\hline 7.1 & The nurse can explain how the infusion pump is provided with power. & .58 & 0.43 & 1.02 \\
\hline 7.7 & $\begin{array}{l}\text { The nurse can discuss why the plug has to be disconnected on the side of } \\
\text { the wall socket and not on the side of the infusion pump. }\end{array}$ & .75 & 0.32 & 0.75 & 0.39 \\
\hline
\end{tabular}

${ }^{a}$ The questions are categorized following the priority and competency requirements. For the different competency requirements, the values and parameters of 3 questions (high priority), 2 questions (medium priority), or 1 question (low priority) are given.

pump competency test. More test questions were answered correctly by nurses with more experience. Moreover, when the difficulty of questions is considered with IRT, experienced nurses score significantly higher than less experienced nurses who score significantly higher than nursing students. The test results do not correspond with the same pattern as the self-declared competency. Nurses with less experience state they are as competent as nurses with more experience. The test results, however, demonstrate a significant difference in the knowledge level of both groups. Regardless of their experience, nurses would accept this competency test as part of their education. Participants agree that a nurse should pass this exam before he or she can work with an infusion pump and that health care will become safer if a nurse must pass this exam before working with an infusion pump.

Although nurses and nursing students agree that a competency test should be passed before working with a device, nursing students agree much more strongly. A possible explanation could be that nursing students feel more assured after passing a test. A positive test result indicates that a nurse has reached a professional standard. ${ }^{29}$ Moreover, it could give students and novice nurses an easier way of indicating that they are not yet competent. Speaking up is important to improve patient safety but is negatively influenced by factors like "fear of conflicts" or "concerns of appearing incompetent." ${ }^{30}$ The obligation to pass a competency test could therefore improve the confidence of nurses and the safety of patients.

Another influence on the acceptability of the competency test could be that nurses think the test needs to be improved before a competency decision is made. Although the test distinguishes between experience levels, it might not be able to provide a reliable pass-fail decision yet. To reach a reliable pass-fail decision, additional research

TABLE 4

\section{Exam Scores of Candidates Following the Classical Test Theory and Item Response Theory}

\begin{tabular}{|c|c|c|c|c|}
\hline \multirow[b]{2}{*}{ Exam score } & Student & 0-5 years of experience & $10+$ years of experience & Total \\
\hline & \multicolumn{4}{|l|}{ Mean (SD) } \\
\hline CTT 20 selected questions & $8.52(2.28)$ & $13.98(2.38)$ & $14.99(2.34)$ & $12.57(3.70)$ \\
\hline IRT 20 selected questions & $-0.97(0.45)$ & $0.27(0.53)$ & $0.55(0.52)$ & $0.33(0.84)$ \\
\hline
\end{tabular}

Abbreviations: CTT, classical test theory; IRT, item response theory. 


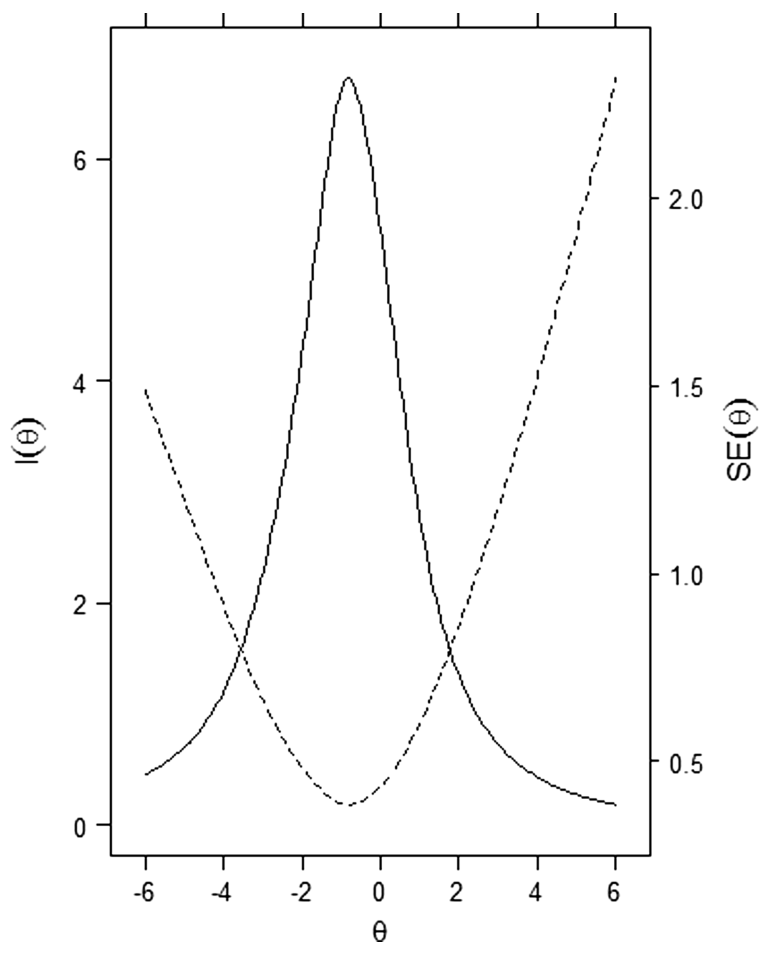

Figure 1 Information curve (solid line) and standard error curve (dashed line) for the complete test as a function of the abilities.

should compare this test with other methods like skill assessment to ensure that the competency is assessed in different ways. Few valid and reliable measuring tools are currently available to assess medical device competency of nurses. ${ }^{31}$ The lack of measurement tools makes it difficult to compare this test with a gold standard. However, the aim of the competency test is to assess whether nurses achieve professional standards. ${ }^{29}$ Therefore, the results of the competency test should be compared with the professional standards and skills of nurses to obtain more information about the correlation. Furthermore, a multimethod approach to determine competency offers a better overall estimate of competency. ${ }^{32}$ When knowledge is compared or combined with skills, a pass-fail norm for future use could be determined.

The competency test could be used for feedback, as well as a pass-fail decision. Effective feedback is important in learning and helps learners achieve educational goals. ${ }^{33}$ In our test, each question is linked to a competency requirement, which makes it possible to link deficiencies in knowledge to those requirements. If the test could take into account possible incorrect evaluation, it could provide nurses with more tailored feedback (eg, by providing more questions for areas in which competency is assessed as insufficient). One possibility for achieving more feedback is to develop a computerized adaptive test (CAT). A CAT more precisely estimates the ability of the test taker after each question and selects a next question based on this estimate. ${ }^{34}$ However, this approach would require the development of more questions and sophisticated analysis. ${ }^{35}$ Therefore, CAT might be more suitable for larger tests and groups, for example, a national competency test before a nurse is allowed to work in practice. The competency requirements and test developed for this study could be a starting point for developing a nationwide test of competency of nurses.

Although the competency test can distinguish between experience of nurses, this study did not investigate the influence on patient safety. There is evidence that training has an impact on patient safety, but no studies are known about the impact of competency tests on safety. ${ }^{13}$ Further research with the competency requirements and test is needed to gain insight into the possible influence on patient safety. General opinion indicates that the development of such competency tests is desired for patient safety (eg, the importance of continuing education has been increasingly emphasized in the literature). ${ }^{36}$ Moreover, a study indicated that $89 \%$ of the public believes that nurses need to demonstrate their competence periodically. ${ }^{37}$

\section{LIMITATIONS}

A limitation of this study is the low number of participants, which restricts the possibility of investigating more specific groups or considering more questions with IRT. However, the combination of CTT and IRT made it possible to select and test the most informative questions, which led to a reliable IRT model. These results provide a reason to continue and extend research with these competency requirements and test. Another limitation of the study was that the link to the online test was sent to nurses by email. Although we emphasized that the test had no consequences and was for research purposes only, it is possible that nurses discussed questions with colleagues or searched for answers. Nevertheless, nurses participated voluntarily and individually in this test, decreasing the chance of discussing questions with colleagues. Moreover, we did not obtain extended background information from the nurses. This study was exploratory research for a national infusion pump competency test that found differences in nurses with different years of experience. Further research should also focus on differences between specialties, amount of use, and the use of different types of infusion pumps.

\section{CONCLUSIONS}

The infusion pump competency test is able to distinguish among nursing students, nurses with 0 to 5 years of experience, and nurses with more than 10 years of experience. This indicates that the competency test could be used to assess competency in practice. Moreover, the competency test is well accepted by nursing students and nurses alike. They agree that health care will become safer if this test must be passed before nurses are allowed to work with an infusion pump. Both findings indicate that competency

Copyright $\odot 2020$ Infusion Nurses Society. Unauthorized reproduction of this article is prohibited. 
testing could be used in daily practice. Tests based on competency requirements make it possible to tailor feedback and training to health care staff. Further development and research of competency tests could save time to ensure nurse competency and could improve patient safety while increasing the time available for patient care.

\section{ACKNOWLEDGMENTS}

The authors thank F. Dinnissen, E. Hagenaars, R. Oosterhof, and A.M.D.E. Timmermans, PhD, for their participation in the infusion pump expert group. They authors also thank Noordhoff Health for their contribution in the infusion pump expert group and their help in the development of the competency test.

\section{REFERENCES}

1. Langelaan M, Broekens MA, de Bruijne MC, et al. Monitor zorggerelateerde schade 2015/2016. NIVEL and EMGO+ Instituut/VUmc. Published 2017. Accessed December 2017. https://www.nivel.nl/ sites/default/files/bestanden/Rapport_Monitor_Zorggerelateerde_ Schade_2017.pdf

2. Giuliano KK. Intravenous smart pumps: usability issues, intravenous medication administration error, and patient safety. Crit Care Nurs Clin North Am. 2018;30(2):215-224. doi:10.1016/j.cnc.2018.02.004

3. Schnock KO, Dykes PC, Albert J, et al. The frequency of intravenous medication administration errors related to smart infusion pumps: a multihospital observational study. BMJ Qual Saf. 2017;26(2):131-140. doi:10.1136/bmjqs- 2015-004465

4. Langelaan M, de Bruijne MC, Baines RJ, et al. Monitor zorggerelateerde schade 2011/2012. EMGO+ Instituut/VUmc and NIVEL. Published 2013. Accessed February 2017. https://www.nivel.nl/sites/default/ files/bestanden/monitor_zorggerelateerde_schade_2011_2012.pdf

5. Taxis K, Barber N. Ethnographic study of incidence and severity of intravenous drug errors. BMJ. 2003;326(7391):684. doi:10.1136/ bmj.326.7391.684

6. Björkstén KS, Bergqvist $M$, Andersén-Karlsson E, Benson L, Ulfvarson J. Medication errors as malpractice-a qualitative content analysis of 585 medication errors by nurses in Sweden. BMC Health Serv Res. 2016;16(1):431. doi:10.1186/s12913-016-1695-97.

7. Amoore JN. A structured approach for investigating the causes of medical device adverse events. J Med Eng. 2014;2014:314138. doi:10.1155/2014/3141388

8. Brand D. Just a piece of equipment? the importance of medical device education. J Perioper Pract. 2012;22(12):380-382. doi:10.1177/175045891602201202

9. Clarkson DM. Medical Device Guidebook: a browser information resource for medical device users. Med Eng Phys. 2017;41:97-102. doi:10.1016/j.medengphy.2017.01.013

10. Cook DA, Hatala R, Brydges R, et al. Technology-enhanced simulation for health professions education: a systematic review and metaanalysis. JAMA. 2011;306(9):978-988. doi:10.1001/jama.2011.1234

11. Gijbels H, O'Connell R, Dalton-O'Connor C, O'Donovan M. A systematic review evaluating the impact of post-registration nursing and midwifery education on practice. Nurse Educ Pract. 2010;10(2):64-69. doi:10.1016/j.nepr.2009.03.01112

12. Wolf ZR. Strategies to reduce patient harm from infusion-associated medication errors: a scoping review. J Infus Nurs. 2018;36(1):58-65. doi:10.1097/NAN.0000000000000263

13. Ward DJ. The role of education in the prevention and control of infection: a review of the literature. Nurse Educ Today. 2011;31(1):9-17. doi:10.1016/j.nedt.2010.03.007
14. Helm RE, Klausner JD, Klemperer JD, Flint LM, Huang E. Accepted but unacceptable: peripheral IV catheter failure. I Infus Nurs. 2015;38(3):189-203. doi:10.1097/NAN.0000000000000100

15. Tsouroufli $\mathrm{M}$, Payne $\mathrm{H}$. Consultant medical trainers, modernising medical careers (MMC) and the European time directive (EWTD): tensions and challenges in a changing medical education context. BMC Med Educ. 2008;8:31. doi:10.1186/1472-6920-8-31

16. Donen N. No to mandatory continuing medical education, yes to mandatory practice auditing and professional educational development. CMAJ. 1998;158(8):1044-1046.

17. Pratt SI, Mueser KT, Wolfe R, Santos MM, Bartels SJ. One size doesn't fit all: a trial of individually tailored skills training. Psychiatr Rehabil J. 2017;40(4):380-386. doi:10.1037/prj0000261

18. Thomsen AS, Bach-Holm D, Kjærbo $H$, et al. Operating room performance improves after proficiency-based virtual reality cataract surgery training. Ophthalmology. 2017;124(4):524-531. doi:10.1016/j. ophtha.2016.11.015

19. Schwieren J, Barenberg J, Dutke S. The testing effect in the psychology classroom: a meta-analytic perspective. Psycho Learn Teach. 2017;16(2):179-196.

20. Pijl-Zieber EM, Barton S, Konkin J, Awosoga O, Caine V. Competence and competency-based nursing education: finding our way through the issues. Nurse Educ Today. 2014;34(5):676-678. doi:10.1016/j. nedt.2013.09.007

21. Miller GE. The assessment of clinical skills/competence/performance. Acad Med. 1990;65(9 suppl):S63-S67. doi:10.1097/00001888199009000-00045

22. Meretoja R, Isoaho H, Leino-Kilpi $H$. Nurse competence scale: development and psychometric testing. J Adv Nurs. 2004;47(2):124-133. doi:10.1111/j.1365-2648.2004.03071.x

23. Clark RE, Feldon D, Merrienboer Jv, Yates K, Early S. Cognitive Task Analysis. 3rd ed. Lawrence Elbraum Associates; 2008.

24. Bloom BS, Engelhart MD, Furst EJ, Hill WH, Krathwohl DR. Taxonomy of Educational Objectives. David McKay Co. Inc.; 1956.

25. Morizot J, Ainsworth AT, Reise SP. Toward modern psychometrics: application of item response theory models in personality research. In: Robins RW, Fraley RC, Krueger RF, eds. Handbook of Research Methods in Personality Psychology. Guilford; 2017:407-423.

26. De Champlain AF. A primer on classical test theory and item response theory for assessments in medical education. Med Educ. 2010;44(1):109-117. doi:10.1111/j.1365-2923.2009.03425.x

27. Yang FM, Kao ST. Item response theory for measurement validity. Shanghai Arch Psychiatry. 2014;26(3):171-177. doi:10.3969/j. issn.1002-0829.2014.03.010

28. Porte PJ, Verweij LM, Dinnissen F, et al. Infusion Technology for Nurses, Basic Proficiency Requirements for the Safe Use of Infusion Technology. NIVEL/EMGO+. Published 2017. Accessed July 2017. https://www.nivel.nl/nl/publicatie/infusion-technology-nurses-basicproficiency-requirements-safe-use-infusion-technology

29. Cowin LS, Hengstberger-Sims C, Eagar SC, Gregory L, Andrew S, Rolley J. Competency measurements: testing convergent validity for two measures. J Adv Nurs. 2008;64(3):272-277. doi:10.1111 /j.1365-2648.2008.04774.x30

30. Okuyama A, Wagner C, Bijnen B. Speaking up for patient safety by hospital-based health care professionals: a literature review. $B M C$ Health Serv Res. 2014;14:61. doi:10.1186/1472-6963-14-6131

31. Meretoja R, Koponen L. A systematic model to compare nurses' optimal and actual competencies in the clinical setting. J Adv Nurs. 2012;68(2):414-422. doi:10.1111/j.1365-2648.2011.05754

32. Flinkman $M$, Leino-Kilpi H, Numminen $O$, Jeon $Y$, Kuokkanen L, Meretoja R. Nurse competence scale: a systematic and psychometric review. J Adv Nurs. 2017;73(5):1035-1050. doi:10.1111/jan.13183

33. Sachdeva AK. Use of effective feedback to facilitate adult learning. J Cancer Educ. 1996;11(2):106-118. doi:10.1080/08858199609528405 
34. Linden WJvd, Glas ACW. Computerized Adaptive Testing. Kluwer Academic Publishers; 2000.

35. Mills CN, Stocking ML. Practical issues in large-scale high-stakes computerized adaptive testing. Educational Testing Service. Published 1995. Accessed February 2018. https://onlinelibrary.wiley.com/doi/epdf/10.1002/j.2333-8504.1995.tb01658.x
36. Gallagher L. Continuing education in nursing: a concept analysis. Nurse Educ Today. 2007;27(5):466-473. doi:10.1016/j.nedt.2006. 08.00737

37. Lundgren BS, Houseman CA. Continuing competence in selected health care professions. I Allied Health. 2002;31(4): 232-240.

\section{STATEMENT OF OWNERSHIP, MANAGEMENT, AND CIRCULATION}

1. Publication Title: Journal of Infusion Nursing. 2. Publication Number: 5032-30. 3. Filing Date: September 30, 2020. 4. Issue Frequency: Bimonthly. 5. Number of Issues Published Annually: 6. 6. Annual Subscription Price: \$177.00. Contact: Stacie Gantz Telephone: 215-521-8309. 7. Complete Mailing Address of Known Office of Publication: Wolters Kluwer Health, Inc., 14700 Citicorp Dr., Bldg. \#3, Hagerstown, MD 21742. 8. Complete Mailing Address of Headquarters or General Business Office of Publisher: Wolters Kluwer Health, Inc.,

Two Commerce Square, 2001 Market Street, Philadelphia, PA 19103. 9. Full Names and Complete Mailing Addresses of Publisher, Editor, and Managing Editor: Publisher: Wolters Kluwer Health, Inc., Two Commerce Square, 2001 Market Street, Philadelphia, PA 19103. Editor: Mary Alexander, MA, RN, CRNI, CAE, FAAN, Editor, Infusion Nurses Society, One Edgewater Dr., Ste. 209, Norwood, MA 02062. Managing Editor: Amy Myers, Lippincott Williams \& Wilkins, Two Commerce Square, 2001 Market St., Philadelphia, PA 19103. 10. Owner: Infusion Nurses Society, One Edgewater Drive, Suite 209, Norwood, MA 02062. 11. Known Bondholders, Mortgagees, and Other Security Holders Owning or Holding 1 Percent or More of Total Amount of Bonds, Mortgages, or Other Securities: none. 12. Tax Status (nonprofit organizations authorized to mail at nonprofit rates): Has not changed during preceding 12 months.

14. Issue Date for Circulation Data Below: July/Aug 2020 43.4.

15. Extent and Nature of Circulation

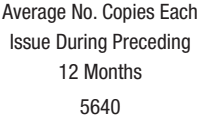

(1) Free or Nominal Rate Outside-County Copies included on PS Form 3541:

(2) Free or Nominal Rate In-County Copies Included on PS Form 3541:

(3) Free or Nominal Rate Copies Mailed at Other Classes Through the USPS:

(4) Free or Nominal Rate Distribution Outside the Mail:

e. Total Free or Nominal Rate Distribution:

f. Total Distribution:

g. Copies not Distributed:

h. Total:

i. Percent Paid:

17. Statement of Ownership will be printed in the $11 / 12 / 2020$ issue.

18. I certify that all information furnished on this form is true and complete.

No. Copies of Single Issue
Published Nearest to
Filing Date
5247
4513
none

250
none
4763

69
none
none
0
69
4832
415
5247
$98.57 \%$

